\title{
RELIABILITY AND EFFICIENCY OF RAINWATER HARVESTING SYSTEMS UNDER DIFFERENT CLIMATIC AND OPERATIONAL SCENARIOS
}

\author{
N. URSINO \& A. GRISI \\ Department ICEA, University of Padova, Italy.
}

\begin{abstract}
Global demand for clean water supply is on the rise due to population growth, climate and land-use change. Resource limitation, climate, leading to increasing water scarcity, demographic and socioinstitutional shifts promote more integrated water management, such as: storm-water harvesting and re-use that may mitigate the risk of water restrictions for urban populations. There is a need to ascertain whether integrated strategies can achieve social and economic goals as well as good-quality ecosystem service and maintenance by long-term monitoring of existing reuse plant, design and feasibility analysis and probabilistic modelling of sustainable rainfall drainage, storage and re-use systems.

Rainwater harvesting (RWH) systems may supply daily non-potable water for irrigation, toilette flushing, car washing and other uses. Optimal storage capacity size should correspond to that tank size for which further increases in size produced only a small increase in reliability. Design is usually performed with reference to tank efficiency, and previous studies evidenced how only in highdemanding scenarios there will be a marked dependence of the RWH system efficiency on the water demand. In this study, data taken from literature, and referred to many different place in the world, are re-examined in light of a new risk model. Efficiency, risk of overflow and risk of waterscarcity of RWH tank are examined under various climatic and operational scenarios (including system size and demand). Efficiency is compared with risk and their suitability as indicators of correct tank design is discussed.
\end{abstract}

\section{INTRODUCTION}

Rainwater reuse in domestic, commercial and industrial applications is often recommended for sustainable urban water management. Key design parameters of rainwater harvesting (RWH) systems are the storage capacity volume of RWH tank, the extension of surfaces where rainwater is collected and then diverted to the tank, and the rate of reuse. Furthermore, since the reliability of RWH systems depends on the rainwater availability, the local precipitation volumes, intermittency and seasonality [1] also affect RWH system performance. Design is usually performed with reference to efficiency of the tank, which in highdemanding scenarios depends on the ratio between water needed and water stored in the tank [2].

The RWH tank is usually the most expensive element of a RWH system. A recent literature review [2] of RWH tanks working under very different environmental and operational conditions [3-8] reveals that two trends exist: for low demand, efficiency does not depend on demand itself; as the demand increases, demand and efficiency of the tank fits to a power function. The interdependence between efficiency and climate characteristics was not explicitly accounted for. 
The probability approach [9], instead provides analytical equations to estimate the risk of failure of components of the urban drainage system based on the statistics of daily or hourly rainfall events. A recent probabilistic model allows the estimate of the risk of failure of multipurpose storage capacities for sustainable urban water management [1]. The model is based on the probabilistic approach [9], and provides closed form solutions for the risk of overflow and the risk of water scarcity of a RWH tank for irrigation and reuse. A slightly modified version of this model is formulated here and risk and efficiency of tanks operating under different climate and demand conditions [2] are evaluated. The results demonstrate that efficiency does not always correspond to low risk of overflow and it is poorly related with the risk of water scarcity in many cases.

\section{MATERIALS AND METHODS}

Figure 1 shows a schematic drainage and reuse system, where a small catchment transforms rainfall into runoff and a drainage network (with negligible storage capacity) collects and diverts runoff toward a storage tank with controlled outflow, or to overflow discharge when the tank is full. During the dry inter-event time, water previously stored in the tank, is reused at constant rate $\left(Q_{0}\right)$.

The meteorological input to the catchment is represented by the probability density functions of rainfall depth $(h)$ and inter-storm interval $(t)$. Following the approach proposed by [9], $h$ and $t$ are modelled as random variables with exponential probability density functions.

$$
\begin{aligned}
& f_{h}=\zeta e^{-\zeta h} \\
& f_{t}=\lambda e^{-} \lambda^{\mathrm{t}}
\end{aligned}
$$

where $\zeta$ is the inverse of expected value of rainfall depth and $\lambda$ is the inverse of expected inter-storm interval.

A modified version of the risk model proposed by [1] is derived hereinafter for the RWH system shown in Fig. 1, where the contributing area $(S)$ of the catchment with runoff coefficient $\phi$ provides the rainfall volume $\phi S h$ to the tank, which has maximum storage capacity $V_{s}$. During the inter-event time $t$ water previously stored in the tank is reused at rate $Q_{0}$. Under the most conservative assumption, the tank is full at the end of the first of two consecutive rainfall events, risk of overflow $R_{f}$ is estimated, as the probability that either the rainfall volume is $\phi S h>V_{s}$, or that two consecutive rainfall events occur in a short period of

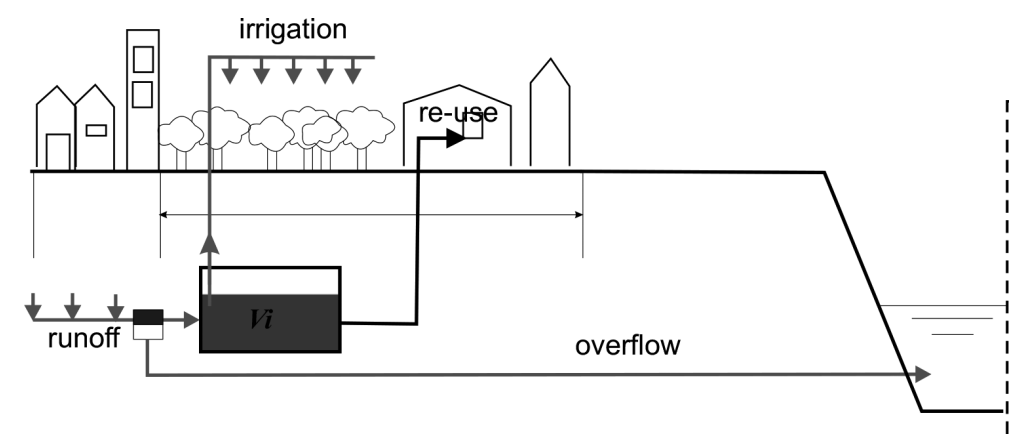

Figure 1: Conceptual model. Schematic representation of catchment, RWH and reuse system. 
time. At the beginning of the second rainfall event, tank storage capacity is $Q_{0} t<V_{s}$ and rainfall volume is $\phi S h>Q_{0} t$. Overflow results in a loss of water resources which occurs with probability $R_{f}$ :

$$
R_{f}=P\left[t \geq V_{s} / Q_{0}\right] \cdot P\left[\varphi S h>V_{s}\right]+P\left[t<V_{s} / Q_{0}\right] \cdot P\left[\varphi S h>Q_{0} t\right]
$$

Combining Equations 1, 2 and 3 the risk of overflow results in the following expression

$$
R_{f}=\frac{a}{a+b} e^{-(a+b)}+\frac{b}{a+b}
$$

where $a$ and $b$ are dimensionless parameters accounting for the characteristics of climate, catchment and RWH system. Namely: $a=\frac{\zeta V s}{\varphi S}$ and $b=\frac{\lambda V s}{Q_{0}}$

Risk of water scarcity $R_{i}$ is evaluated, under the most conservative assumption that the reservoir is empty at the beginning of the last rainfall event,the probability that rainfall volume is $\phi S h<V_{s}$ and the time to the next rainfall event is greater than $\phi S h / Q_{0}$, or that rainfall volume is $\phi S h \geq V_{s}$ but that the next rainfall event occurs after complete tank draw-down, i.e., $V_{s} / Q_{0}$.

$$
R_{i}=P\left[h<V_{s} /(\phi S)\right] \cdot P[t>\phi S h / Q]+P\left[h \geq V_{s} /(\phi S)\right] P\left[t>V_{s} / Q_{0}\right]
$$

Combining Eqns 1, 2 and 5, the risk of water scarcity results in the following expression

$$
R_{f}=\frac{b}{a+b} e^{-(a+b)}+\frac{a}{a+b}
$$

When either $a$ or $b$ are large, meaning that $V_{s}>>\phi S \zeta^{-1}$ or $V_{s}>Q_{0} \lambda^{-1}$, thus, the tank storage capacity is much larger than the average runoff volume $\varphi \mathrm{S} \zeta^{-1}$ or than the average reuse volume $Q_{0} \lambda^{-1}$, eqns (4) and (6) reduce to

$$
R_{f}^{\prime}=\frac{b}{a+b}
$$

and

$$
R_{i}^{\prime}=\frac{b}{a+b}
$$

where $R_{f}^{\prime}+R_{i}^{\prime}=1$.

\section{RESULTS}

The performance of numerous RWH tanks was recently classified [2] on the basis of two nondimensional parameters: the demand ratio and efficiency. The demand ratio is defined as the ratio between the annual demand and the annually collected rainwater, while efficiency is the capacity of the RWH system to satisfy the water demand. A threshold demand ratio (equal to 0.8 ) discriminates between tanks characterized by high efficiency which does not depend on the demand ratio, and tanks characterized by progressively decreasing efficiency with increasing demand ratio. Risk of overflow [4] and risk of water scarcity [6] are estimated here for the same set of tanks [2]. The average annual rainfall $\zeta^{-1}$ is estimated as the ratio between the mean annual rainfall and the number of rainy days. Whereas $\lambda^{-1}$ is estimated as the ratio between the length of the rainy season and the number of rainy days. 


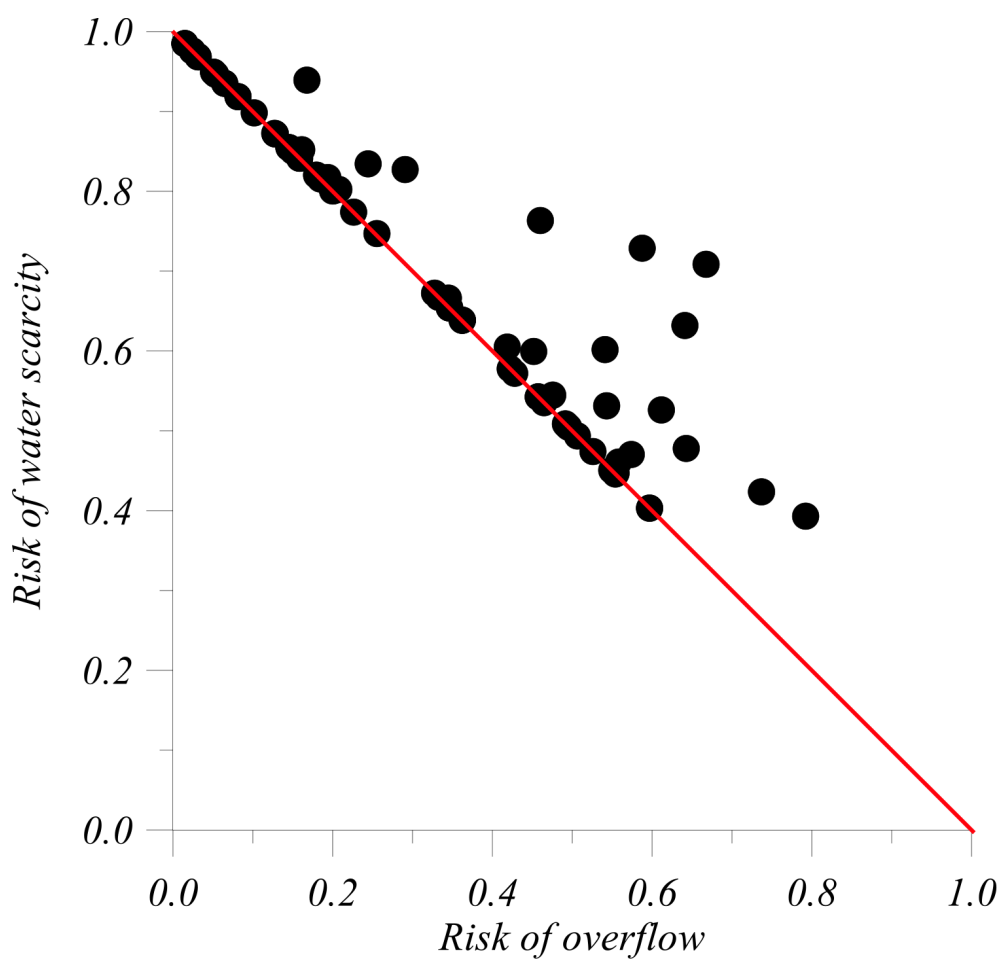

Figure 2: Risk of overflow vs Risk of water scarcity for differing operating and climate conditions.

Figure 2 shows Risk of overflow vs Risk of water scarcity for differing operating and climate conditions. Risk of overflow and risk of water scarcity seem to be inter-changeable indicators of tank performance in many cases, holding the interrelation $R_{f}=1-R_{i}$, meaning that $e^{-(a+b)}$ is negligible and thus $V_{s}<<\zeta^{-1} \phi \mathrm{S}$ (large tank) or $V_{s}>>Q_{0} \lambda^{-1}$ (low demand). Although, risk of water scarcity is in a few cases higher than risk of overflow, suggesting that climatic conditions, such as long dry spells, may be the major reason of inefficient performance of RWH tanks, whereas the risk of overflow, thus the risk of losses of re-usable resources does not seem to be responsible for the lack of reuse water.

Risk of overflow and risk of water scarcity are plotted together with efficiency versus the demand fraction in Fig. 3. Efficiency and risk of overflow exhibit similar decreasing trend with demand ratio between 0.8 and 50, even though efficiency does not account explicitly for inter-annual rainfall variability. Risk of overflow is not systematically overestimated, neither under-estimated by efficiency, but it exhibits larger dispersion than efficiency, possibly due to the uncertainty related to the variable climatic conditions, thus demonstrating that climate variability may overwhelm deterministic efficiency. The risk of water scarcity is high for tank operating at any demand ratio, indicating that water availability when needed is mainly threatened by long dry spells and possibly that the assumption of empty tank at the beginning of two consecutive rain events is too restrictive and thus that cumulative contribution of consecutive rain events of any entity may be crucial for tank performance. 


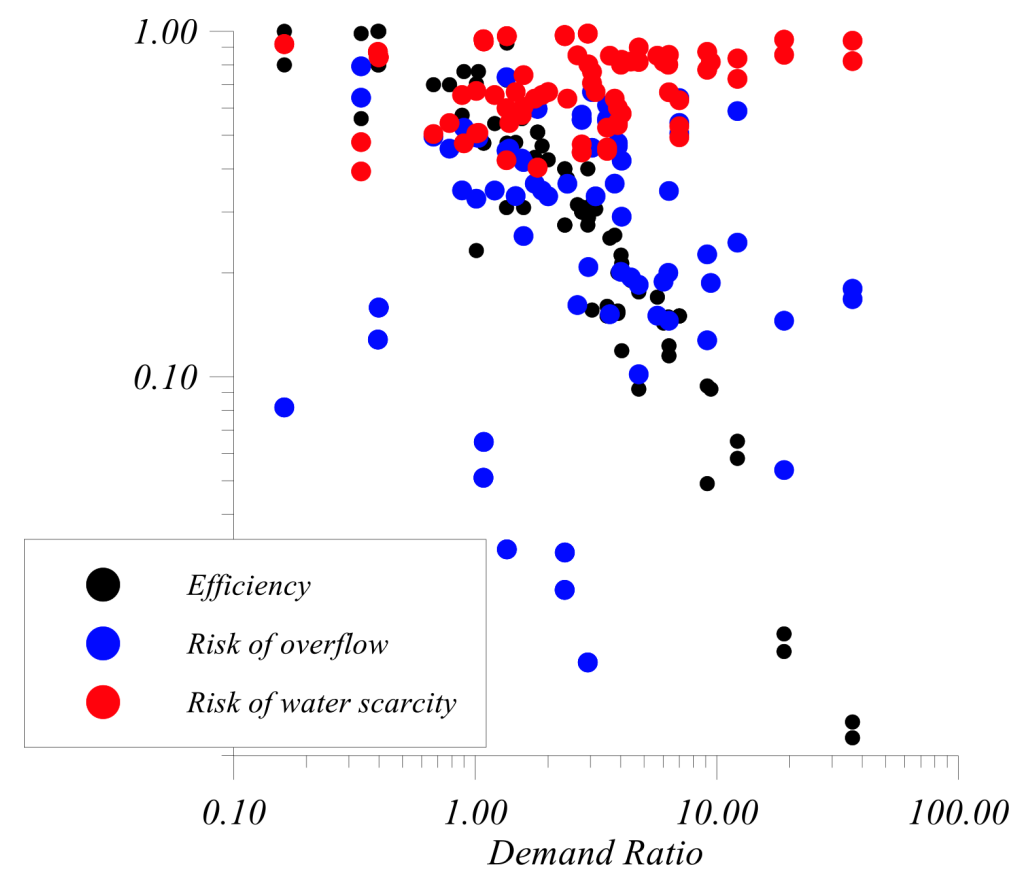

Figure 3: Efficiency [2], Risk of overflow and Risk of water scarcity vs demand ratio for differing operating and climate conditions.

\section{DISCUSSION}

The analysis of a large number of tanks, under different operating and cli- mate conditions indicates that efficiency and risk of overflow may be used as indicators of tank performance. Risk of overflow decrease with demand ratio, although (1) risk of overflow is more scattered than efficiency when plotted vs demand ratio, demonstrating the relevance of rainfall uncertainty in evaluating tank performance and (2) the risk of water scarcity is much higher than both: risk of overflow and efficiency in many cases, pointing at the relevance of rainwater availability during dry periods in designing SWH systems.

Climate is a major determinant of RWH system efficiency and risk analysis accounts for climate forcing in addition to operating conditions and design characteristics, providing an estimate of RWH tank performance not always coincident with efficiency. When the risk of overflow and risk of water scarcity are confronted with efficiency, no threshold demand ratio, distinguishing between small and large tank is evident, and rather, the results demonstrate the high variability of tank performances under differing clismate and operating conditions.

\section{REFERENCES}

[1] Ursino, N., Risk analysis of sustainable urban drainage and irrigation. Advances in Water Resources, 83, pp. 277-284, 2015. http://dx.doi.org/10.1016/j.advwatres.2015.06.011

[2] Sanches Fernandes, L., Terencio, D. \& Pacheco, F., Rainwater harvesting systems for low demanding applications. Science of the Total Environment, 529, pp. 91-100, 2015. http://dx.doi.org/10.1016/j.scitotenv.2015.05.061 
[3] Mehrabadi, M., Saghafian, B. \& Fashi, F., Assessment of residential rainwater harvesting efficiency for meeting non-potable water demands in three climate conditions. Resources Conservation and Recycling, 73, pp. 86-93, 2013. http://dx.doi.org/10.1016/j.resconrec.2013.01.015

[4] Palla, A., Gnecco, I. \& Lanza, L., Non-dimensional design parameters and performance assessment of rainwater harvesting systems. Journal of Hydrology, 401, pp. 65-76, 2011. http://dx.doi.org/10.1016/j.jhydrol.2011.02.009

[5] Mwenge Kahinda, J., Taigbenu, A. \& Boroto, R., Domestic rainwater harvesting as an adaptation measure to climate change in south africa. Physics and Chemistry of the Earth, Parts A/B/C, 35(13-14), pp. 742-751, 2010. http://dx.doi.org/10.1016/j.pce.2010.07.004

[6] Abdulla, F. \& Al-Shareef, A., Roof rainwater harvesting systems for household water supply in jordan. Desalination, 243(1-3), pp. 195-207, 2009. http://dx.doi.org/10.1016/j.desal.2008.05.013

[7] Ghisi, E., da Fonseca Tavares, D. \& Rocha, V.L., Rainwater harvesting in petrol stations in braslia: potential for potable water savings and investment feasibility analysis. Resources, Conservation and Recycling, 54(2), pp. 79-85, 2009. http://dx.doi.org/10.1016/j.resconrec.2009.06.010

[8] Zhang, Y., Chen, D., Chen, L. \& Ashbolt, S., Potential for rainwater use in high-rise buildings in australian cities. Journal of Environmental Management, 91, pp. 222-226, 2009.

http://dx.doi.org/10.1016/j.jenvman.2009.08.008

[9] Adams, B. \& Papa, F., Urban Stormwater Management Planning with Analytical Probabilistic Models, John Wiley Sons: New York, 2000. 